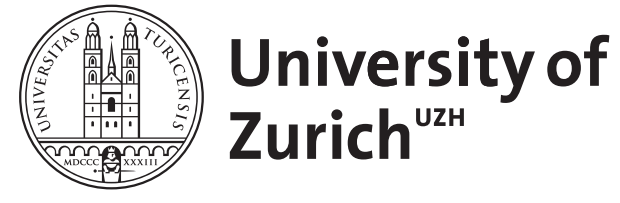

\title{
High altitude and cancer mortality
}

\author{
Thiersch, Markus ; Swenson, Erik R
}

\begin{abstract}
Thiersch, Markus, and Erik R. Swenson. High altitude and cancer mortality. High Alt Med Biol 00:000-000, 2017.-Humans living at high altitude (HA) are exposed to chronic (hypobaric) hypoxia. Despite the permanent stress of hypoxic exposure, humans populating HA areas have reduced cancer mortality over a broad spectrum of cancer types. In fact, the majority of the physiological adaptive processes at HA occurring in response to hypoxia might be the driving force for reduced cancer mortality at HA. In this review, we summarize epidemiological and animal studies that compare cancer incidence and cancer mortality between HA and low altitude or between hypoxia and normoxia, respectively. We discuss the potential role of oxygen-independent and oxygen-dependent mechanisms that might contribute to reduced cancer mortality at HA. Reactive oxygen species and their detoxification as well as the hypoxiainducible factors are especially promising targets and may be related to why cancer mortality is reduced at HA. In addition, we briefly discuss two aspects with a proven impact on tumorigenesis, namely the immune system and tumor surveillance as well as HA-induced metabolic changes. Further animal and clinical studies are clearly needed to explain why cancer mortality is reduced at HA and to decide whether HA or hypoxia-based therapeutic approaches could be implemented for cancer treatment. However, exposure to HA activates multiple adaptive mechanisms (oxygen independent and oxygen dependent) sharing common pathways as well as activating counteracting pathways, which complicate the identification of specific HA-induced mechanisms of tumor suppression.
\end{abstract}

DOI: https://doi.org/10.1089/ham.2017.0061

Posted at the Zurich Open Repository and Archive, University of Zurich

ZORA URL: https://doi.org/10.5167/uzh-148109

Journal Article

Accepted Version

Originally published at:

Thiersch, Markus; Swenson, Erik R (2018). High altitude and cancer mortality. High Altitude Medicine Biology, 19(2):116-123.

DOI: https://doi.org/10.1089/ham.2017.0061 


\title{
High Altitude and Cancer Mortality
}

\author{
Markus Thiersch ${ }^{1}$ and Erik R. Swenson ${ }^{2,3}$
}

Affiliations: ${ }^{1}$ Institute of Veterinary Physiology, Vetsuisse Faculty, and Zurich Center for Integrative Human Physiology (ZIHP), University of Zurich, Winterthurerstrasse 260, 8057 Zurich, Switzerland. ${ }^{2}$ Dept of Medicine, Division of Pulmonary, Critical Care and Sleep Medicine, University of Washington, Seattle, WA, USA. ${ }^{3}$ Medical Service, Veterans Affairs Puget Sound Health Care System, Seattle, WA, USA.

\begin{abstract}
Humans living at high altitude (HA) are exposed to chronic (hypobaric) hypoxia. Despite the permanent stress of hypoxic exposure, humans populating high altitude areas have reduced cancer mortality over a broad spectrum of cancer types. In fact, the majority of the physiological adaptive processes at HA occurring in response to hypoxia might be the driving force for reduced cancer mortality at HA. In this review, we summarize epidemiological and animal studies that compare cancer incidence and cancer mortality between high and low altitude or between hypoxia and normoxia, respectively. We discuss the potential role of oxygen-independent and oxygen-dependent mechanisms that might contribute to reduced cancer mortality at HA. Reactive oxygen species (ROS) and their detoxification as well as the hypoxia-inducible factors (HIFs) are especially promising targets and may be related to why cancer mortality is reduced at HA. Additionally, we briefly discuss two aspects with a proven impact on tumorigenesis, namely the immune system and tumor surveillance as well as HA induced metabolic changes. Further animal and clinical studies are clearly needed to explain why cancer mortality is reduced at HA and to decide if HA or hypoxia-based therapeutic approaches could be implemented for cancer treatment. However, exposure to HA activates multiple adaptive mechanisms (oxygen-independent and dependent) sharing common pathways as well as activating counteracting pathways, which complicate the identification of specific HA-induced mechanisms of tumor suppression.
\end{abstract}




\section{Introduction}

Living at high altitude (HA) and the associated hypobaric hypoxia (Burtscher 2014) requires considerable adaptation to a potentially inhospitable environment. However, even adapted highlanders are not completely protected from this physiological challenge and may develop altitude related diseases such as chronic mountain sickness. Notably other diseases like diabetes and obesity occur less frequently in highlanders. Surprisingly, it has been reported within the last decades that humans living at high altitude show either reduced cancer incidence or mortality. That suggests that HA exposure may have an impact on distinct cancer phases; namely initiation (incidence) or proliferation and metastasis (mortality). Here, we summarize the results of epidemiological and animal studies and discuss mechanisms that may account for a possible benefit of high altitude living in altering cancer incidence or mortality.

\section{Human Studies}

In 1974 and 1975, three studies reported an inverse relationship of HA and cancer mortality in humans (Burton 1975; Eckhoff and others 1974; Mason and Miller 1974). However, these early studies did not consider potential confounders such as industrialization, urbanization, economic status and ethnicity, which could cause false correlations between cancer and HA. In further published work over the next several decades, several studies that corrected for potential cofounders have confirmed these findings (Amsel and others 1982; Burton and Cornhill 1977; Hart 2010; 2011a; 2011b; Hart and Hyun 2012; Van Pelt 2003; Weinberg and others 1987). A recent study compared cancer mortality for Caucasians living at high and low altitude counties in the US (Hart 2011a) and showed a clear correlation between HA and reduced overall cancer mortality. However, types of cancer may respond differently to HA. Indeed, several reports that analyzed site-specific cancer mortality suggested that mortality from lymphoma, breast (Youk and others 2012), lung, tongue, mouth and larynx (Amsel and others 1982; Van Pelt 2003) is reduced whereas other cancers such as liver and cervix remain unaffected or are even increased (e.g. melanoma due to the higher 
background radiation (Aceituno-Madera and others 2011; Boscoe and Schymura 2006); placental choriocarcinoma (Reshetnikova and others 1996)) (see also table 1). Additionally, carotid body tumor (paraganglioma) incidence is increased at high altitude (Arias-Stella and Valcarcel 1973; Astrom and others 2003). Although hypoxia causes chief cell hyperplasia (Arias-Stella and Valcarcel 1976), carotid body tumors have less malignant behavior than those tumors at low altitudes. and the ratio of female to male patients with these tumors increases from 2:1 at low altitude to 8.3:1 at HA (Rodriguez-Cuevas and others 1998).

In 2015, Simeonov and Himmelstein particularly analyzed the association of HA and cancer incidence and reported decreasing lung and breast (but not colorectal and prostate) cancer incidence with elevation (Simeonov and Himmelstein 2015) suggesting that HA protects cells of at least some tissues from undergoing malignant transformation. However, the Simeonov and Himmelstein study defined smokers (the biggest risk factor for lung cancer development) as individuals consuming more than 100 cigarettes in their lifetime without further differentiating between moderate and heavy smokers (Simeonov and Himmelstein 2015). The number of daily cigarettes clearly correlates with lung cancer risk (Law and others 1997) and if smoking habits (i.e. number of cigarettes per day) substantially differed between high and low altitude counties the results of this study could be biased. Nevertheless, the effect size of lung cancer incidence is possibly strong enough to statistically justify the observed relationship between lung cancer incidence and HA.

\section{Animal Studies}

In 1970 and 1974 , Mori-Chavez et al. exposed mice to very high altitude $(4,540 \mathrm{~m})$ for a prolonged period of time after exposure to sub-lethal levels of x-rays and found a reduced overall incidence of neoplasms (Mori-Chavez and others 1970; 1974), especially thymic lymphoma and granulocytic leukemia, but an increased incidence of lung cancer compared to low altitude controls (Mori-Chavez and others 1970; 1974). However, the reduced life span of mice exposed to HA (Mori-Chavez and others 1970; 1974) might indirectly cause a reduced frequency of neoplasms because the mice could have died before a neoplasm developed. Similar to x-ray induced malignancies, the spontaneous onset of leukemia in C58 mice declines with increasing altitude (Mori-Chavez 1958) whereas spontaneous lung cancer 
incidence increases (Mori-Chavez 1962). The difference in lung cancer incidence between human highlanders (reduced at $\mathrm{HA}$ ) and mice (increased at $\mathrm{HA}$ ) might be indeed related to cigarette consumption suggesting that smoking habits at HA should be considered. In addition to increased lung cancer incidence, metastasis in a model of intravenously injected ascites carcinoma cells increases at HA (Mori-Chavez and Salazar 1965). In contrast, it was shown in rat and mouse models that primary tumor growth rate as well as metastasis rate are reduced (Kulish 1987) and that the efficacy of chemotherapy is increased (Kulish 1985; Kulish and Galkina 1983) at HA, Recently, Sung et al. studied tumor incidence in two mouse models of spontaneous cancer, namely $\mathrm{p}^{-{ }^{-/}}$and $\mathrm{APC}^{\mathrm{Min} /+}$, as well as in a chemically inducible skin carcinogenesis model. They observed delayed tumor formation in normobaric hypoxic mice ( $10 \%$ oxygen; equivalent to an extreme altitude of approximately $5,500-6,000$ meters above sea level) (Sung and others 2011) under standardized laboratory conditions independent of other environmental factors (e.g. atmospheric pressure, radiation etc.). In the thymus of hypoxia-exposed mice reduced levels of oxidative DNA damage were observed. These data in rodents directly link oxygen concentration and tumor incidence giving strong support to the epidemiological data in humans. Another link of oxygen availability and tumor incidence has been reported in hypoxia-resistant naked mole rats that live under extreme hypoxic conditions (Schumacher and others 2015) and are able to sustain several minutes of total anoxia (Park and others 2017). They have been long thought to develop no tumors at all (Schumacher and others 2015), although some cancer cases have been reported recently (Delaney and others 2016; Piersigilli and Meyerholz 2016). Nevertheless, their very strong protection from cancer might be dependent on oxygen-related metabolic reprogramming (Park and others 2017), which will be briefly discussed below. 


\section{High Altitude Dependent Mechanisms of Cancer Incidence}

\section{and Mortality Reduction}

\subsection{Oxygen independent environmental factors}

The causes of reduced cancer incidence or mortality at HA are difficult to identify and might be quite tumor specific. HA positively correlates with ultraviolet-B (UV-B) exposure and negatively with oxygen levels and pollution, all of which have been discussed as causative or contributory. It has been hypothesized (Hayes 2010) that reduced cancer mortality at HA (e.g. lymphoma, breast, lung, etc. (Boscoe and Schymura 2006)) might be driven by UV-B dependent vitamin $D$ production. The beneficial effects and the anti-carcinogenic properties of solar UV-B and increased vitamin D production have been nicely reviewed elsewhere (Bikle 2016). The vitamin D receptor is frequently (but not ubiquitously) expressed in tumor cells and the loss of its expression during tumor evolution is a poor prognostic factor (Bikle 2016; Narvaez and others 2014; Santagata and others 2014). Clinical trials suggest an inverse association of colorectal cancer incidence and vitamin D intake and/or serum levels (Bikle 2016). However, colorectal cancer incidence did not correlate with HA in a recent study (Simeonov and Himmelstein 2015). Evidence for and against vitamin D dependent protection from breast cancer has been reported (Bikle 2016) supported by a mild to moderate association of breast cancer incidence and HA (Simeonov and Himmelstein 2015). Finally, no effect of vitamin D as well as no association to HA has been shown in prostate cancer (Bikle 2016; Simeonov and Himmelstein 2015). Consequently, a protective role of elevated vitamin D levels against cancer mortality seems possible, but remains to be proven.

Apart from influences of vitamin D, other parameters vary with altitude, such as radon and airborne particulate matter. Particulate matter concentration generally declines with altitude and has been defined as a group 1 carcinogen by the International Agency for Research on Cancer (IARC 2013) to increase lung cancer incidence (Hamra 2014). However, the association of lung cancer incidence and high altitude seems to be independent of potentially carcinogenic variables such as particulate matter, radon, UV-B, and other oxygen independent factors as shown in a statistical model that estimated the odds if the replacement 
of HA with other environmental factors (e.g. particulate) is superior (Simeonov and Himmelstein 2015).

Inextricably linked to living at high altitude is the mild hypocapnic respiratory alkalosis that arises from the ventilatory response and adaptation to hypoxia. The higher the resident altitude the greater is the hyperventilation and associated alkalosis. A considerable amount of cellular and animal work has shown that various means of imposing mild to moderate alkalotic conditions, either by base (bicarbonate) supplementation or lower ambient $\mathrm{CO}_{2}$ lead to reduced carcinogenesis (Ibrahim-Hashim and others 2012), decreased development and spread of metastases (Azzarito and others 2016; Ibrahim Hashim and others 2011; Robey and Nesbit 2013), and greater efficacy of certain cancer drug therapies (Tavares-Valente and others 2013). Cancer cells are highly metabolic and hypoxia resistant, in part mediated by HIF induced changes in metabolism. These include a switch to a very high rate of oxidative and non-oxidative glycolysis. This well-recognized Warburg effect generates large amounts of $\mathrm{CO}_{2}$ and lactic acid in supplying cancer cells with short carbon chain substrates for protein, lipid and nucleic acid synthesis. As part of this strategy, malignant cells must dispose of these acids by active transport into the extracellular fluid (ECF) by up-regulation of numerous membrane acid-base transporters, such as the monocarboxylate transporter (MCT-1) for lactate and the tumor-associated carbonic anhydrase (CA) isozymes, CA IX and XII (Swenson 2016). In addition to disposal of these acids to limit end-product metabolic inhibition, acidification of the ECF acts to reduce tumor surveillance and killing by host immune cells discussed below. Thus it can be postulated that the relative greater ECF alkalinity at high altitude may favorably suppress malignant cell initiation and spread, as was postulated by (Burton 1975) but without defining how this might occur.

\subsection{Oxygen and Reactive Oxygen Species (ROS)}

Simeonov and Himmelstein (2015) attributed their observation of reduced lung cancer incidence in humans to hypobaric hypoxia and even hypothesize that oxygen per se (due to the formation of reactive oxygen species ROS) is carcinogenic in lung tissue as the organ that experiences the highest levels of oxygen as the site of oxygen uptake. What is surprising about these human data is that other organ sites of cancer, which physiologically have lower 
$\mathrm{PO}_{2} \mathrm{~S}$ than the lung owing to their position in the oxygen cascade from the environment to the periphery, are not protected.

Similarly, the authors of the aforementioned study of hypoxia-exposed mice with reduced cancer incidence hypothesized that physiological oxygen levels may be carcinogenic due to the formation of reactive oxygen species (ROS) resulting in fatal DNA damage (Sung and others 2011). To support their interpretation, they discuss the reported increased cancer incidence of premature infants that received ventilatory support with excessive oxygen (Sung and others 2011) suggesting that at least very high concentrations of oxygen in predisposed subjects may be carcinogenic. However, hyperbaric oxygen therapy is occasionally used in cancer therapies (e.g. breast cancer), and so far no evidence of oxygen-dependent increased risk of tumor recurrence or stimulation of tumor progression has been found (Moen and Stuhr 2012). In fact, Hatfield et al. showed that increased inspired oxygen (hyperoxia) decreases intratumoral hypoxia resulting in decreased immunosuppression and enhanced recruitment of anti-tumorigenic T-cells to the tumor microenvironment (Hatfield and others 2015). As a consequence, the survival of mice was prolonged and both, primary (lung) tumor and (breast) metastasis regressed with oxygen supplementation (Hatfield and others 2015). Importantly, serum ROS levels are even increased instead of reduced upon acute exposure to HA (Murray and Horscroft 2016; Sinha and others 2009) and the ROS levels of highlanders chronically exposed to ambient hypoxia may exceed those of lowlanders (Sinha and others 2009), although in this study the low- and highland subjects may have been of different ethnicity.

Clearly, ROS are involved in oxidative stress and DNA damage and thus may result in oncogenesis, but a balanced level of ROS is essential to mediate cell physiological responses (Sabharwal and Schumacker 2014). To promote their damaging potential ROS levels have to exceed and overcome cellular anti-oxidant scavenging systems, which involve superoxide dismutases, catalase, and glutathione peroxidase to name but a few. In fact, the oxidative defense system displays a higher level of activity in subjects populating HA regions (Sinha and others 2009), most likely in response to enhanced ROS formation. Therefore, it cannot be excluded that improved ROS detoxification instead of reduced oxygen-dependent ROS generation rate accounts for hypoxia-dependent reduced tumor incidence at HA. 


\subsection{Oxygen and The Hypoxia Inducible Factor (HIF) Pathway}

With increasing altitude the barometric pressure decreases, resulting in reduced inspired oxygen partial pressure $\left(\mathrm{pO}_{2}\right)$. Consequently, alveolar oxygen partial pressure is reduced - approximately $50 \%$ at an altitude of 5800 meters (Peacock 1998). At sea level, the arterial oxygen partial pressure reaches almost alveolar levels during gas exchange. However, the reduced oxygen partial pressure at very high altitude is insufficient to fully oxygenate and equilibrate the blood with alveolar air during its passage through the pulmonary capillaries. Diffusion limitation and impaired gas exchange further increase the difference between blood oxygen partial pressure at sea level and at high altitude (Peacock 1998). At approximately $5800 \mathrm{~m}$ the arterial oxygen partial pressure nearly equals the mixed venous oxygen partial pressure at sea level. The difference between arterial and mixed venous $\mathrm{pO}_{2}$ is much smaller at high altitude (35 to $21 \mathrm{mmHg}$ ), respectively when compared to sea level (100 to $40 \mathrm{mmHg}$ ) (Peacock 1998). Despite physiological compensations such as increased cardiac output, ventilation, hemoglobin, and angiogenesis via VEGF (Paralikar and Paralikar 2010), nonetheless there remains a degree of reduced oxygen availability to the tissues (Gassmann and Muckenthaler 2015). In fact increased cardiac output as a short-term physiological adaptation reduces the passage time of blood through the lung capillaries impairing oxygen uptake by erythrocytes. Consequently, tissue (including tumors) experience reduced oxygen levels at high altitude.

At the cellular level the tightly oxygen-regulated, heterodimeric hypoxia-inducible factors (HIFs) quickly and precisely respond to the oxygen availability and regulate a large number of cellular responses to hypoxia by up- and down-regulating the transcription of over 1000 genes involved in hypoxia tolerance (Ema and others 1997; Flamme and others 1997; Semenza and others 1991; Semenza and Wang 1992; Tian and others 1997). Prolylhydroxylases (PHDs) are oxygen-sensitive hydroxylases that regulate the stability of HIFalpha subunits resulting in rapid protein degradation when oxygen is sufficiently available (Kaelin and Ratcliffe 2008). At the first glance, the observation of oxygen-dependent reduced cancer mortality (or incidence) at HA is surprising because tumor hypoxia per se is rather a supportive factor for tumor growth and the development of aggressive phenotypes in many cancers (Brown 2007; Vaupel and Mayer 2007). In combination with tumor-associated or 
therapy-induced anemia, aggressive phenotypes develop even faster and HIF1 and 2 have been reported to promote tumor growth and metastasis (Liu and others 2015; Semenza 2010; Zhao and others 2015).

Although HIF1 and 2 regulate many similar genes, both transcription factors have been also shown to regulate distinct target genes and cellular pathways (Loboda and others 2010), which seems to be also reflected by their site-specific role in tumorigenesis. As an example, HIF1 critically contributes to breast cancer malignancy and HIF1 inhibition reduces breast cancer metastasis (Wong and others 2012). In contrast, HIF2 has been reported to play a critical role in clear cell renal cell carcinoma (Biswas and others 2010; Kondo and others 2003; Raval and others 2005) and might be a potential therapeutic target (Cho and Kaelin 2016). However, other groups have argued that HIF1 rather than HIF2 promotes renal carcinogenesis ( $\mathrm{Fu}$ and others $2011 ; 2013$; Xu and others 2010) emphasizing the complexity of the disease. It has been also reported that loss of HIF-1 expression may promote renal cell carcinoma proliferation (Shen and others 2011) suggesting that at least in some tissues stabilized HIF might be tumor suppressive. In fact, a study reported that evolutionary selected variants of HIF pathway genes - namely EGLN1 (encoding for PHD2) and EPAS1 (encoding for HIF-2 alpha) - in Tibetans have a role in this population's higher lung cancer risk (Lanikova and others 2016). High altitude-adapted variants of EGLN2 with D4E and C127S polymorphisms increase PHD2 activity leading to HIF-alpha degradation under hypoxic conditions (Lorenzo and others 2014; Simonson and others 2010). These data suggest, that the stabilization of HIF-1 and HIF-2 in hypobaric hypoxia at HA might contribute to reduced mortality in at least some types of cancer.

\subsection{Tumor Metabolism and the Organism}

Adaptations to acute and chronic HA result in hypoxia-driven metabolic changes including those that involve glucose and lipid metabolism. Obesity and type 2 diabetes mellitus are metabolic disorders associated with an increased cancer risk (Arnold and others 2016; Goday and others 2015), but are less prevalent in humans living at HA (Diaz-Gutierrez and others 2016; Woolcott and others 2014; Woolcott and others 2016). Highlanders have reduced plasma glucose concentrations (Augustin and others 2015) that might protect them from hyperglycemia-associated increased cancer risk (Duan and others 2014). Additionally, 
lipids are essential for energy homeostasis, membrane assembly and regulation of cancerassociated signaling pathways (Chen 2011; Fritz and Fajas 2010; Hashmi and others 2015). Since high plasma lipid concentrations are associated with increased cancer risk (Allott and Hursting 2015; Gong and others 2014), reduced plasma fatty acid concentrations in highlanders (Woolcott and others 2015) as well as their lower cholesterol concentrations may contribute to the reduced cancer mortality at HA. A more detailed consideration of metabolic alterations in tumor cells as well in healthy tissue at HA and their influence on cancer mortality has been recently published (Thiersch and others 2017).

\subsection{The Immune System and Tumor Surveillance}

The many and variable responses of the neuro-immune system to acute and chronic hypoxia are predicted to have a possible impact on tumor incidence and mortality. Hypoxia has significant effects on infection risks and prevalence, both negative and positive (for review see (Mazzeo and Swenson 2014). In part, this is by modulation of the innate and acquired arms of the immune system, the most interesting leading to a much-reduced risk of tuberculosis. The immune system additionally can recognize neoantigens on malignantly transformed cells as foreign and act to repress tumor growth and metastatic spread. It is reasonable to ask whether the immune-modulating effects of hypoxia on microbial pathogens might also extend to the immunosurveillance of cancer. Dendritic cells and lymphocytes are critical elements in host defense against malignancy and the functions of both are altered with hypoxia. Although hypoxia in general may depress lymphocyte-mediated functions involved in cancer recognition, hypoxia and HIF-1 alpha stimulation of natural killer cell tumor surveillance (Groth and others 2011; Wang and Wu 2009) may be more important and underlie the epidemiological findings of reduced cancer at high altitude. Cancer immuneediting, i.e. the different three stages of tumor cell elimination equilibrium and escape (3E) (Swann and Smyth 2007), shows that the immune system is a double-edged sword during tumorigenesis. Initially eliminating malignant cells and keeping the myriad immune cells in equilibrium, the immune system actually supports tumor malignancy by chronic inflammation after cancer cells have escaped immunosurveillance. It might be possible that hypoxia enhances the efficacy of the immune system prior to tumor formation (improved elimination) and/or reduces chronic tumor inflammation after tumor formation. 


\section{Future Work and Conclusions}

HA potentially impacts on both, cancer incidence and mortality. Patients with prolonged survival and reduced mortality, due treatments delaying the progression rather than curing the disease, are over-represented in prevalence analyses. That might also happen if HA reduces tumor malignancy and metastasis and increases patient survival. Thus, separating these different cancer phases can be complicated in epidemiological analyses.

In our opinion, there is currently little evidence that ambient oxygen (21\%) at sea level per se is carcinogenic - at least in healthy subjects - as several oxygen detoxification pathways keep ROS formation tightly balanced. In patients and animals with genetic (or other health-related) predisposition, oxygen may contribute to cancer formation - when ROS are excessively produced or not sufficiently detoxified. The data on ROS levels in hypoxia exposed animals and in humans populating elevated areas are contradictory and more information particularly about ROS formation and detoxification in cancer patients at HA is required. In the light of the aforementioned publication by Lanikova and colleagues (Lanikova and others 2016), the HIF-pathway may be involved in HA-dependent reduced cancer incidence. Since the control of ROS formation is also regulated by HIFs, their interactions may offer more insight into differences in cancer biology HA. A better understanding of the role of hypoxia-mediated changes in metabolism as well as in immune system function in cancer surveillance may also be important in explaining the reduced incidence of many cancers and differences in tumorigenesis at HA.

In conclusion, exposure to HA has been shown to reduce cancer incidence as well as mortality and reduced oxygen levels may at least partially account for these effects. However, the mechanisms that protect from tumor initiation and ameliorate disease progression remain to be fully identified.

\section{Acknowledgements}

The authors thank Dr. Alexander Seymer (University of Salzburg, Austria) for statistical counseling. We acknowledge the financial support of the Swiss National Science Foundation, 
Marie-Louise von Muralt Foundation, Krebsliga Switzerland and the Zurich Center for Integrative Human Physiology (ZIHP) to MT and from the United States Department of Veterans Affairs to ERS. We apologize to all those authors whose original or review articles could not be cited due to space limitation.

The authors declare no conflict of interests.

\section{References}

Aceituno-Madera P, Buendia-Eisman A, Olmo FJ, Jimenez-Moleon JJ, SerranoOrtega S. (2011). [Melanoma, altitude, and UV-B radiation]. Actas Dermosifiliogr 102,199-205.

Allott EH, Hursting SD. (2015). Obesity and cancer: mechanistic insights from transdisciplinary studies. Endocrine-Related Cancer 22,R365-R386.

Amsel J, Waterbor JW, Oler J, Rosenwaike I, Marshall K. (1982). Relationship of site-specific cancer mortality rates to altitude. Carcinogenesis 3,461-5.

Arias-Stella J, Valcarcel J. (1973). The human carotid body at high altitudes. Pathol Microbiol (Basel) 39,292-7.

Arias-Stella J, Valcarcel J. (1976). Chief cell hyperplasia in the human carotid body at high altitudes; physiologic and pathologic significance. Hum Pathol 7,36173.

Arnold M, Leitzmann M, Freisling H, Bray F, Romieu I, Renehan A, Soerjomataram I. (2016). Obesity and cancer: An update of the global impact. Cancer Epidemiology 41,8-15.

Astrom K, Cohen JE, Willett-Brozick JE, Aston CE, Baysal BE. (2003). Altitude is a phenotypic modifier in hereditary paraganglioma type 1: evidence for an oxygen-sensing defect. Hum Genet 113,228-37.

Augustin LS, Kendall CW, Jenkins DJ, Willett WC, Astrup A, Barclay AW, Bjorck I, Brand-Miller JC, Brighenti F, Buyken AE and others. (2015). Glycemic index, glycemic load and glycemic response: An International Scientific Consensus Summit from the International Carbohydrate Quality Consortium (ICQC). Nutr Metab Cardiovasc Dis 25,795-815.

Azzarito T, Lugini L, Spugnini EP, Canese R, Gugliotta A, Fidanza S, Fais S. (2016). Effect of Modified Alkaline Supplementation on Syngenic Melanoma Growth in CB57/BL Mice. PLoS One 11,e0159763.

Bikle DD. (2016). Extraskeletal actions of vitamin D. Marrow 2016, Vol 1376 1376,29-52.

Biswas S, Troy H, Leek R, Chung YL, Li JL, Raval RR, Turley H, Gatter K, Pezzella F, Griffiths JR and others. (2010). Effects of HIF-1alpha and HIF2alpha on Growth and Metabolism of Clear-Cell Renal Cell Carcinoma 786-0 Xenografts. J Oncol 2010,757908.

Boscoe FP, Schymura MJ. (2006). Solar ultraviolet-B exposure and cancer incidence and mortality in the United States, 1993-2002. Bmc Cancer 6.

Brown JM. (2007). Tumor hypoxia in cancer therapy. Methods in enzymology 435,297-321.

Burton AC. (1975). Cancer and altitude. Does intracellular pH regulate cell division? European journal of cancer 11,365-71. 
Burton AC, Cornhill JF. (1977). Correlation of cancer death rates with altitude and with the quality of water supply of the 100 largest cities in the United States. J Toxicol Environ Health 3,465-78.

Burtscher M. (2014). Effects of Living at Higher Altitudes on Mortality: A Narrative Review. Aging and Disease 5,274-280.

Chen J. (2011). Multiple signal pathways in obesity-associated cancer. Obes Rev 12,1063-70.

Cho H, Kaelin WG. (2016). Targeting HIF2 in Clear Cell Renal Cell Carcinoma. Cold Spring Harb Symp Quant Biol 81,113-121.

Delaney MA, Ward JM, Walsh TF, Chinnadurai SK, Kerns K, Kinsel MJ, Treuting PM. (2016). Initial Case Reports of Cancer in Naked Mole-rats (Heterocephalus glaber). Vet Pathol 53,691-6.

Diaz-Gutierrez J, Martinez-Gonzalez MA, Pons Izquierdo JJ, Gonzalez-Muniesa P, Martinez JA, Bes-Rastrollo M. (2016). Living at Higher Altitude and Incidence of Overweight/Obesity: Prospective Analysis of the SUN Cohort. PLoS One 11,e0164483.

Duan W, Shen X, Lei J, Xu Q, Yu Y, Li R, Wu E, Ma Q. (2014). Hyperglycemia, a neglected factor during cancer progression. Biomed Res Int 2014,461917.

Eckhoff ND, Shultis JK, Clack RW, Ramer ER. (1974). Correlation of leukemia mortality rates with altitude in the United States. Health physics 27,377-80.

Ema M, Taya S, Yokotani N, Sogawa K, Matsuda Y, Fujii-Kuriyama Y. (1997). A novel bHLH-PAS factor with close sequence similarity to hypoxia-inducible factor 1alpha regulates the VEGF expression and is potentially involved in lung and vascular development. Proceedings of the National Academy of Sciences of the United States of America 94,4273-8.

Flamme I, Frohlich T, von Reutern M, Kappel A, Damert A, Risau W. (1997). HRF, a putative basic helix-loop-helix-PAS-domain transcription factor is closely related to hypoxia-inducible factor- 1 alpha and developmentally expressed in blood vessels. Mechanisms of development 63,51-60.

Fritz V, Fajas L. (2010). Metabolism and proliferation share common regulatory pathways in cancer cells. Oncogene 29,4369-77.

Fu L, Wang G, Shevchuk MM, Nanus DM, Gudas LJ. (2011). Generation of a mouse model of Von Hippel-Lindau kidney disease leading to renal cancers by expression of a constitutively active mutant of HIF1alpha. Cancer Res 71,6848-56.

Fu L, Wang G, Shevchuk MM, Nanus DM, Gudas LJ. (2013). Activation of HIF2alpha in kidney proximal tubule cells causes abnormal glycogen deposition but not tumorigenesis. Cancer Res 73,2916-25.

Gassmann M, Muckenthaler MU. (2015). Adaptation of iron requirement to hypoxic conditions at high altitude. J Appl Physiol (1985) 119,1432-40.

Goday A, Barneto I, Garcia-Almeida JM, Blasco A, Lecube A, Grivalos C, de Icaya PM, de las Penas R, Monereo S, Vazquez L and others. (2015). Obesity as a risk factor in cancer: A national consensus of the Spanish Society for the Study of Obesity and the Spanish Society of Medical Oncology. Clinical \& Translational Oncology 17,763-771.

Gong Y, Dou LJ, Liang J. (2014). Link between obesity and cancer: role of triglyceride/free fatty acid cycling. European Review for Medical and Pharmacological Sciences 18,2808-2820.

Groth A, Kloss S, von Strandmann EP, Koehl U, Koch J. (2011). Mechanisms of tumor and viral immune escape from natural killer cell-mediated surveillance. J Innate Immun 3,344-54.

Hamra. (2014). Outdoor Particulate Matter Exposure and Lung Cancer: A Systematic Review and Meta-Analysis (vol 122, pg 906, 2014). Environmental Health Perspectives 122,A294-A294. 
Hart J. (2010). Mean cancer mortality rates in low versus high elevation counties in Texas. Dose-response : a publication of International Hormesis Society 8,448-55.

Hart J. (2011a). Cancer mortality for a single race in low versus high elevation counties in the u.s. Dose-response : a publication of International Hormesis Society 9,348-55.

Hart J. (2011b). Cancer mortality in six lowest versus six highest elevation jurisdictions in the u.s. Dose-response : a publication of International Hormesis Society 9,50-8.

Hart J, Hyun S. (2012). Cancer mortality, state mean elevations, and other selected predictors. Dose-response : a publication of International Hormesis Society 10,58-65.

Hashmi S, Wang Y, Suman DS, Parhar RS, Collison K, Conca W, Al-Mohanna F, Gaugler R. (2015). Human cancer: is it linked to dysfunctional lipid metabolism? Biochim Biophys Acta 1850,352-64.

Hatfield SM, Kjaergaard J, Lukashev D, Schreiber TH, Belikoff B, Abbott R, Sethumadhavan S, Philbrook P, Ko K, Cannici R and others. (2015). Immunological mechanisms of the antitumor effects of supplemental oxygenation. Sci Transl Med 7,277ra30.

Hayes DP. (2010). Cancer protection related to solar ultraviolet radiation, altitude and vitamin D. Medical hypotheses 75,378-82.

IARC. (2013). IARC: Outdoor air pollution a leading environmental cause of cancer deaths. https://http://www.iarc.fr/en/media-centre/iarcnews/pdf/pr221_E.pdf Press Release 221.

Ibrahim Hashim A, Cornnell HH, Coelho Ribeiro Mde L, Abrahams D, Cunningham J, Lloyd M, Martinez GV, Gatenby RA, Gillies RJ. (2011). Reduction of metastasis using a non-volatile buffer. Clin Exp Metastasis 28,841-9.

Ibrahim-Hashim A, Cornnell HH, Abrahams D, Lloyd M, Bui M, Gillies RJ, Gatenby RA. (2012). Systemic buffers inhibit carcinogenesis in TRAMP mice. J Urol 188,624-31.

Kaelin WG, Jr., Ratcliffe PJ. (2008). Oxygen sensing by metazoans: the central role of the HIF hydroxylase pathway. Mol Cell 30,393-402.

Kondo K, Kim WY, Lechpammer M, Kaelin WG, Jr. (2003). Inhibition of HIF2alpha is sufficient to suppress pVHL-defective tumor growth. PLoS Biol 1,E83.

Kulish OP. (1985). [Effect high-altitude conditions on the antitumor activity of cyclophosphane and its action on lymphoid tissue cells]. Eksp Onkol 7,60-3.

Kulish OP. (1987). [Characteristics of the metastatic spread of transplanted tumors under high-altitude conditions]. Eksp Onkol 9,73-5.

Kulish OP, Galkina KA. (1983). [Effect of high-altitude hypoxia on the effectiveness of chemotherapy in tumors]. Biull Eksp Biol Med 95,33-5.

Lanikova L, Reading NS, Hu H, Tashi T, Burjanivova T, Shestakova A, Siwakoti B, Thakur BK, Pun CB, Sapkota A and others. (2016). Evolutionary selected Tibetan variants of HIF pathway and risk of lung cancer. Oncotarget.

Law MR, Morris JK, Watt HC, Wald NJ. (1997). The dose-response relationship between cigarette consumption, biochemical markers and risk of lung cancer. Br J Cancer 75,1690-3.

Liu ZJ, Semenza GL, Zhang HF. (2015). Hypoxia-inducible factor 1 and breast cancer metastasis. Journal of Zhejiang University-Science B 16,32-43.

Loboda A, Jozkowicz A, Dulak J. (2010). HIF-1 and HIF-2 transcription factors-similar but not identical. Mol Cells 29,435-42.

Lorenzo FR, Huff C, Myllymaki M, Olenchock B, Swierczek S, Tashi T, Gordeuk V, Wuren T, Ri-Li G, McClain DA and others. (2014). A genetic mechanism for Tibetan high-altitude adaptation. Nat Genet 46,951-6.

Mason TJ, Miller RW. (1974). Cosmic radiation at high altitudes and U.S. cancer mortality, 1950-1969. Radiation research 60,302-6. 
Mazzeo C, Swenson ER. (2014). The Immune System. High Altitude: Human Adaptation to Hypoxia. EDS. Swenson E.R. and Bartsch P.,271-284.

Moen I, Stuhr LEB. (2012). Hyperbaric oxygen therapy and cancer-a review. Targeted Oncology 7,233-242.

Mori-Chavez P. (1958). Spontaneous leukemia at high altitude in C58 mice. J Natl Cancer Inst 21,985-97.

Mori-Chavez P. (1962). Development of spontaneous pulmonary tumors at high altitude in strain A mice. J Natl Cancer Inst 28,55-73.

Mori-Chavez P, Salazar M. (1965). Study of metastasis after the intravenous injection of ascites carcinoma number 678 into $\mathrm{C} 3 \mathrm{H}$ mice at high altitude. $\mathrm{J}$ Natl Cancer Inst 35,193-9.

Mori-Chavez P, Upton AC, Salazar M, Conklin JW. (1970). Influence of altitude on late effects of radiation in RF-Un mice: observations on survival time, blood changes, body weight, and incidence of neoplasms. Cancer research 30,91328.

Mori-Chavez P, Upton AC, Salazar M, Conklin JW. (1974). Influence of transitory, as compared with permanent, high-altitude exposure on the pathogenesis of spontaneous and $x$-ray-induced neoplasms in RF-Un mice. Cancer Res 34,328-36.

Murray AJ, Horscroft JA. (2016). Mitochondrial function at extreme high altitude. Journal of Physiology-London 594,1137-1149.

Narvaez CJ, Matthews D, LaPorta E, Simmons KM, Beaudin S, Welsh J. (2014). The impact of vitamin $D$ in breast cancer: genomics, pathways, metabolism. Frontiers in Physiology 5.

Paralikar SJ, Paralikar JH. (2010). High-altitude medicine. Indian J Occup Environ Med 14,6-12.

Park TJ, Reznick J, Peterson BL, Blass G, Omerbasic D, Bennett NC, Kuich P, Zasada C, Browe BM, Hamann W and others. (2017). Fructose-driven glycolysis supports anoxia resistance in the naked mole-rat. Science 356,307-311.

Peacock AJ. (1998). ABC of oxygen: oxygen at high altitude. BMJ 317,1063-6.

Piersigilli A, Meyerholz DK. (2016). The "Naked Truth": Naked Mole-Rats Do Get Cancer. Vet Pathol 53,519-20.

Raval RR, Lau KW, Tran MG, Sowter HM, Mandriota SJ, Li JL, Pugh CW, Maxwell $\mathrm{PH}$, Harris AL, Ratcliffe PJ. (2005). Contrasting properties of hypoxiainducible factor 1 (HIF-1) and HIF-2 in von Hippel-Lindau-associated renal cell carcinoma. Mol Cell Biol 25,5675-86.

Reshetnikova OS, Burton GJ, Milovanov AP, Fokin El. (1996). Increased incidence of placental chorioangioma in high-altitude pregnancies: hypobaric hypoxia as a possible etiologic factor. Am J Obstet Gynecol 174,557-61.

Robey IF, Nesbit LA. (2013). Investigating mechanisms of alkalinization for reducing primary breast tumor invasion. Biomed Res Int 2013,485196.

Rodriguez-Cuevas S, Lopez-Garza J, Labastida-Almendaro S. (1998). Carotid body tumors in inhabitants of altitudes higher than 2000 meters above sea level. Head Neck 20,374-8.

Sabharwal SS, Schumacker PT. (2014). Mitochondrial ROS in cancer: initiators, amplifiers or an Achilles' heel? Nature Reviews Cancer 14,709-721.

Santagata S, Thakkar A, Ergonul A, Wang B, Woo T, Hu R, Harrell JC, McNamara G, Schwede M, Culhane AC and others. (2014). Taxonomy of breast cancer based on normal cell phenotype predicts outcome. Journal of Clinical Investigation 124,859-870.

Schumacher LN, Husson Z, St. John Smith E. (2015). The naked mole-rat as an animal model in biomedical research: current perspectives. Open Access Anim. Physiol. 7,137-148. 
Semenza GL. (2010). Defining the role of hypoxia-inducible factor 1 in cancer biology and therapeutics. Oncogene 29,625-634.

Semenza GL, Nejfelt MK, Chi SM, Antonarakis SE. (1991). Hypoxia-inducible nuclear factors bind to an enhancer element located $3^{\prime}$ to the human erythropoietin gene. Proceedings of the National Academy of Sciences of the United States of America 88,5680-4.

Semenza GL, Wang GL. (1992). A nuclear factor induced by hypoxia via de novo protein synthesis binds to the human erythropoietin gene enhancer at a site required for transcriptional activation. Molecular and cellular biology 12,544754.

Shen C, Beroukhim R, Schumacher SE, Zhou J, Chang M, Signoretti S, Kaelin WG, Jr. (2011). Genetic and functional studies implicate HIF1alpha as a 14q kidney cancer suppressor gene. Cancer Discov 1,222-35.

Simeonov KP, Himmelstein DS. (2015). Lung cancer incidence decreases with elevation: evidence for oxygen as an inhaled carcinogen. Peerj 2.

Simonson TS, Yang Y, Huff CD, Yun H, Qin G, Witherspoon DJ, Bai Z, Lorenzo FR, Xing J, Jorde LB and others. (2010). Genetic evidence for high-altitude adaptation in Tibet. Science 329,72-5.

Sinha S, Ray US, Tomar OS, Singh SN. (2009). Different adaptation patterns of antioxidant system in natives and sojourners at high altitude. Respiratory Physiology \& Neurobiology 167,255-260.

Sung HJ, Ma WZ, Starost MF, Lago CU, Lim PK, Sack MN, Kang JG, Wang PY, Hwang PM. (2011). Ambient Oxygen Promotes Tumorigenesis. Plos One 6.

Swann JB, Smyth MJ. (2007). Immune surveillance of tumors. J Clin Invest 117,1137-46.

Swenson ER. (2016). Hypoxia and Its Acid-Base Consequences: From Mountains to Malignancy. Adv Exp Med Biol 903,301-23.

Tavares-Valente D, Baltazar F, Moreira R, Queiros O. (2013). Cancer cell bioenergetics and $\mathrm{pH}$ regulation influence breast cancer cell resistance to paclitaxel and doxorubicin. J Bioenerg Biomembr 45,467-75.

Thiersch M, Swenson ER, Haider T, Gassmann M. (2017). Reduced Cancer Mortality at High Altitude: The Role of Glucose, Lipids, Iron and Physical Activity. Exp Cell Res.

Tian H, McKnight SL, Russell DW. (1997). Endothelial PAS domain protein 1 (EPAS1), a transcription factor selectively expressed in endothelial cells. Genes \& development 11,72-82.

Van Pelt WR. (2003). Epidemiological associations among lung cancer, radon exposure and elevation above sea level - A reassessment of Cohen's county level radon study. Health Physics 85,397-403.

Vaupel P, Mayer A. (2007). Hypoxia in cancer: significance and impact on clinical outcome. Cancer metastasis reviews 26,225-39.

Wang JS, Wu CK. (2009). Systemic hypoxia affects exercise-mediated antitumor cytotoxicity of natural killer cells. J Appl Physiol (1985) 107,1817-24.

Weinberg CR, Brown KG, Hoel DG. (1987). Altitude, radiation, and mortality from cancer and heart disease. Radiation research 112,381-90.

Wong CC, Zhang H, Gilkes DM, Chen J, Wei H, Chaturvedi P, Hubbi ME, Semenza GL. (2012). Inhibitors of hypoxia-inducible factor 1 block breast cancer metastatic niche formation and lung metastasis. J Mol Med (Berl) 90,803-15.

Woolcott OO, Ader M, Bergman RN. (2015). Glucose homeostasis during short-term and prolonged exposure to high altitudes. Endocr Rev 36,149-73.

Woolcott OO, Castillo OA, Gutierrez C, Elashoff RM, Stefanovski D, Bergman RN. (2014). Inverse association between diabetes and altitude: a cross-sectional study in the adult population of the United States. Obesity (Silver Spring) 22,2080-90. 
Woolcott OO, Gutierrez C, Castillo OA, Elashoff RM, Stefanovski D, Bergman RN. (2016). Inverse association between altitude and obesity: A prevalence study among andean and low-altitude adult individuals of Peru. Obesity (Silver Spring) 24,929-37.

Xu K, Ding Q, Fang Z, Zheng J, Gao P, Lu Y, Zhang Y. (2010). Silencing of HIF1alpha suppresses tumorigenicity of renal cell carcinoma through induction of apoptosis. Cancer Gene Ther 17,212-22.

Youk AO, Buchanich JM, Fryzek J, Cunningham M, Marsh GM. (2012). An ecological study of cancer mortality rates in high altitude counties of the United States. High altitude medicine \& biology 13,98-104.

Zhao J, Du F, Shen G, Zheng F, Xu B. (2015). The role of hypoxia-inducible factor-2 in digestive system cancers. Cell Death \& Disease 6. 